\title{
Capsule Commentary on Ranard et al., Crowdsourcing-Harnessing the Masses to Advance Health and Medicine, a Systematic Review
}

\author{
Sarah Nickoloff, MD \\ Division of General Internal Medicine, , Zablocki VA Medical Center, Milwaukee, WI, USA.
}

$\mathrm{J}$ Gen Intern Med 29(1):186

DOI: $10.1007 / \mathrm{s} 11606-013-2620-0$

(c) Society of General Internal Medicine 2013

$\mathrm{W}$ hile crowdsourcing is a research method that is over two centuries old, it has not been traditionally used in medical research. Crowdsourcing turns to the public for help. Current examples include the Audubon Society's Christmas Bird Count, the Galaxy Zoo project, ${ }^{1}$ in which the public helps classify galaxies, and a whale call classification project. $^{2}$ Crowdsourcing uses the power of many, employing the collective wisdom and resources of the crowd to solve problems.

Ranard et al.'s systematic review on crowdsourcing found surprisingly few studies. ${ }^{3}$ Among the 21 they identified, there were four distinct categories of research: problem solving, data processing, surveillance/monitoring, and surveying. Examples of projects using crowdsourcing include predicting protein folding structures (problem solving), classifying polyps on computed tomography (CT) colonography images (data processing) and tracking influenza outbreaks (surveillance) in near real time. The authors found five benefits of crowdsourcing, including quality, cost, volume, speed, and developing novel science. For example, many eyes reviewing colonography results found more polyps, thus improving quality. Costs are minimal, just those to set up the web portal. Crowdsourcing has the potential to reach hundreds of thousands of participants, generating a large volume response. Problems that might take one person months to decipher can be solved quickly. For example, protein folding problems were sometimes solved in minutes once released to the crowd. Additionally, the unique perspectives of the diverse participants may suggest novel new approaches to the task. Some important problems with using crowdsourcing for medical research include lack of information about the crowd (demographics) and a need for consistent reporting of the experimental setup. There are limitations on the type of research that could be conducted; research that requires informed consent would be impractical, for example. There are also significant ethical issues; what is it reasonable to expose the crowd to? Predicting potential harm for participants may be difficult when little is known about who they are.

With the advent of the internet, crowdsourcing has more potential than ever before; it presents an easy and efficient way to engage the public in research and health surveillance. Like any research methodology, crowdsourcing needs to start with the right question for the approach; however, it could be another viable tool for researchers to use when designing projects.

Conflict of Interest: The author declares no conflict of interest.

Corresponding Author: Sarah Nickoloff, MD; Division of General Internal Medicine, Zablocki VA Medical Center, Milwaukee, WI 53295, USA (e-mail: Sarah.nickoloff@va.gov).

\section{REFERENCES}

1. Lintott C, Schawinski K, Bamford S, et al. Galaxy Zoo 1: data release of morphological classifications for nearly 900,000 galaxies. Mon Not R Astron Soc. 2011;410(1):166-78. doi:10.1111/j.1365-2966.2010.17432.x.

2. Sayigh L, Guick N, Hastie G, et al. Repeated call types in short-finned pilot whales, Globicephala macrorhynchus. Mar Mamm Sci. 2012;29(2):312-24. doi:10.1111/j.1748-7692.2012.00577.x.

3. Ranard BL, Ha YP, Meisel ZF, Asch DA, Hill SS, Becker LB, Seymour AK, Merchant RM. Crowdsourcing-harnessing the masses to advance health and medicine, a systematic review. J Gen Intern Med. 2013. doi:10.1007/s11606-013-2536-8. 